\title{
2885. Sensitivity of beam-column element stiffness matrix to the crack parameters
}

\author{
Peiman Davari Dolatabadi ${ }^{1}$, Karen Khanlari ${ }^{2}$, Mohsen Ghafory Ashtiany ${ }^{3}$, \\ Mahmood Hosseini ${ }^{4}$ \\ ${ }^{1}$ Department of Civil Engineering, Science and Research Branch, Islamic Azad University, Tehran, Iran \\ ${ }^{2}$ Central Tehran Branch, IAU, Tehran, Iran \\ ${ }^{3,4}$ IIEES, Tehran, Iran \\ ${ }^{2}$ Corresponding author \\ E-mail: ${ }^{1}$ pdavarid@yahoo.com, ${ }^{2}$ Khanlari.kaaren@gmail.com, ${ }^{3}$ ashtiany@iiees.ac.ir, \\ ${ }^{4}$ mahmood.hosseini@gmail.com
}

Received 13 November 2017; received in revised form 3 January 2018; accepted 20 February 2018 DOI https://doi.org/10.21595/jve.2018.19397

Check for updates

Copyright $(2018$ Peiman Davari Dolatabadi, et al. This is an open access article distributed under the Creative Commons Attribution License, which permits unrestricted use, distribution, and reproduction in any medium, provided the original work is properly cited.

\begin{abstract}
In this article, a new cracked beam-column element stiffness matrix is proposed through static condensation method. Seven dimensionless coefficients are introduced and applied for a sensitivity analysis in different damage scenarios. The accuracy of this proposed stiffness matrix is verified, and compared to the other available methods. The variation of each stiffness component due to the conversion of crack parameters is assessed and shown in different graphs. This study reveals that cracking has a maximum stiffness reduction of $30 \%$ in the beam-column elements with rectangular cross sections and the damaged elements remain stable until the crack depth is below $80 \%$ of the section depth.
\end{abstract}

Keywords: crack modeling, sensitivity analysis, static condensation.

\section{Introduction}

Crack modeling and identifying constitute the important aspects in damage detection studies. A crack is defined by its location, effective length and depth, named crack parameters. Each one of the crack parameters directly affects the stiffness components. In general, a crack is modeled through FEM [1-3], stiffness reduction [4-11], and fracture mechanics [12-17] methods. Many researchers have sought and seek to find a relation between crack parameters and vibrational components like stiffness, natural frequencies and mode shapes. The Christides and Barr [6] approach, where, element stiffness around the crack is calculated in terms of distance from the center of the crack, is applied in many studies [8, 10, 11]. Sinha, et al. [7] considered linear trend for stiffness variation in the cracked region and proposed a simplified method of cracking subjects to transverse vibration by applying shape functions. Caddemi and Caliò [5] introduced an equation to the Bernoulli beam element stiffness matrix in the presence of several cracks where, the stiffness matrix is calculated based on the cracked beam vibration modes. Caddemi et al. [9] proposed a Timoshenko beam model with the rotational and translational discontinuity, which is based on modeling shear and flexural stiffness discontinuity in the form of distributed Dirac delta and Hyvsid functions. In their study, an equation is developed that provides a relation between element deformation and shape functions, which yields an explicit form of the stiffness matrix. Labib et al. [18] obtained natural frequencies by applying a rotational spring model, including partial Gaussian elimination and the Wittrick-Williams algorithm to model crack elements, where in this process, dynamic stiffness matrices of order four are obtained in a recursive manner, according to the number of cracks. The same authors [19] applied natural frequency degradations and simulated noise free and contaminated measurements in order to locate a single crack in a frame. Differences between uncracked and cracked frequencies is obtained through theoretical analysis and real measurements. Mehrjoo et al. [20] applied the Betty theory together with the ideas of conjugated beam and introduced an equation for the cracked beams regardless of the rotational moment of inertia and shear deformation. Model reduction through static condensation method is an approach 
applied in damage detection. Guyan and Irons are the first to propose the condensation approach for the deletion of unwanted degrees of freedom in 1965. Since late 1960s, this approach has been and is being widely applied in many static and dynamic problems, like component mode synthesis, Eigen problem analysis of large models and experimental mode expansion [21]. Static condensation is an extension of the Gauss elimination algorithm [22]. A recursive method based on static condensation to locate damage based on measured modal frequencies is applied by Ghee Koh et al. [23, 24] where a physical property adjustment model updating method is used. Implementing this method requires only a few modes measured from the damaged structure. Li et al. [25] proposed a method for locating and estimating structural damage in 2D and 3D analytical models of buildings. Damage in this context, is defined in terms of changes in element stiffness. The condensed stiffness matrix of a structure is estimated for damage detection.

In this study with the assistant of static condensation method, a new close form equation is proposed for stiffness matrix of cracked beam-column element. Sensitivity of stiffness components are studied through seven introduced dimensionless coefficients and the results are illustrated in different graphs.

\section{Stiffness matrix of a cracked beam-column element}

In this context, a crack is defined by its location $(\eta L)$, effective length $(\xi L)$ and effective depth $\left(h_{e f f}\right)$, which are named crack parameters. Each one of these parameters directly affects the stiffness components.

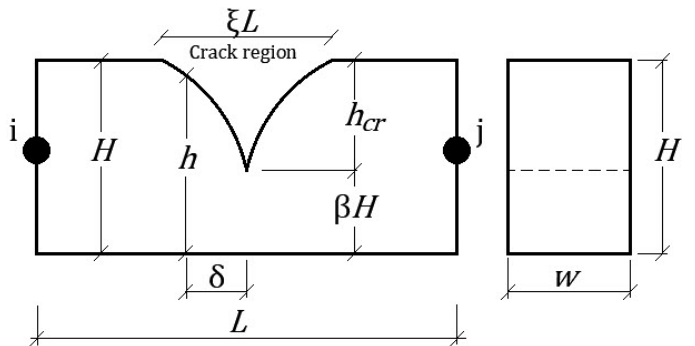

Fig. 1. Cracked element and element section

\subsection{Effective crack length}

Effective crack length is approximated through Eq. (1) [7]:

$\xi L=3 H$,

where, $\xi L$ is the effective crack length, independent of crack location and depth. A more accurate equation based on Sinha et al. [7] is developed here as:

$\xi L=\frac{1.5 H}{1-\beta^{3}} \ln \left(\frac{1}{\beta^{3}}\right)$,

where, $1-\beta$ is the crack to section depth ratio.

\subsection{Effective crack depth}

By considering linear variation in stiffness changes within the above effective crack length, section height in the cracked region is calculated as follows: 
$\frac{h}{H}=\sqrt[3]{\beta^{3}+\frac{4\left(1-\beta^{3}\right)^{2}}{3 \ln \left(\frac{1}{\beta^{3}}\right)} \frac{\delta}{H^{\prime}}}$

where, $\delta$ is the distance from the crack centre along its length, $h$ is the section height at distance $\delta$ and $1-\beta$ is the crack to section depth ratio. Section heights within the crack region in different damage scenarios are plotted in Fig. 2. Effective crack depth $\left(h_{e f f}\right)$ is obtained in a manner that the area below the graph of Eq. (3) becomes equal to that of Eq. (4) within $0 \leq \frac{\delta}{H} \leq \frac{0.75 H}{1-\beta^{3}} \ln \left(\frac{1}{\beta^{3}}\right)$ limit:

$h_{e f f}=\frac{3 H}{4} \frac{\left(1-\beta^{4}\right)}{\left(1-\beta^{3}\right)}$.

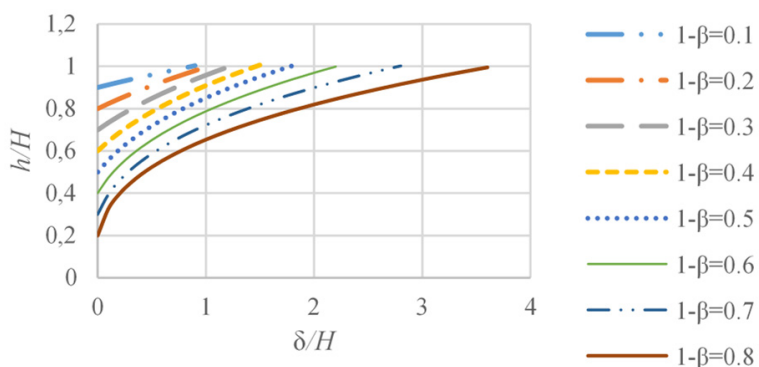

Fig. 2. Element section height near crack, Eq. (3)

\subsection{Cracked beam-column element stiffness matrix}

A concentrated open crack in a beam-column element is expressed by an element with twelve DOFs, Fig. 3. The crack effective length and depth are obtained through Eqs. (2)-(4), respectively. Through a model reduction approach of static condensation, crack sides' DOFs (d7 to d12) are condensed and a new cracked element stiffness matrix is obtained. Each component of the condensed stiffness matrix is divided by its relevant component of the intact stiffness matrix which yields seven dimensionless coefficients expressed through Eq. (5), as follows:

$\emptyset=\frac{k_{\text {cracked }_{11 n}}}{k_{11_{n}}}, \quad \emptyset_{1_{n}}=\frac{k_{\text {cracked }_{11 n}}}{k_{22_{n}}}, \quad \emptyset_{2 n}=\frac{k_{\text {cracked }_{23 n}}}{k_{23_{n}}}, \emptyset_{3 n}=\frac{k_{\text {cracked }_{26 n}}}{k_{26_{n}}}$,

$\emptyset_{4 n}=\frac{k_{\text {cracked }_{33 n}}}{k_{33_{n}}}, \emptyset_{5_{n}}=\frac{k_{\text {cracked }_{36 n}}}{k_{36_{n}}}, \emptyset_{6_{n}}=\frac{k_{\text {cracked }_{66 n}}}{k_{66_{n}}}$,

where, $k_{\text {cracked }_{i j n}}$ and $k_{i j_{n}}$ are the cracked and intact element stiffness components, respectively. The active stiffness coefficients in different DOFs are tabulated in Table 1. The DOFs of the subject beam - column element is shown in Fig. 4.

Table 1. Stiffness coefficients in different DOFs

\begin{tabular}{|c|c|c|c|c|c|c|}
\hline DOF & 1 & 2 & 3 & 4 & 5 & 6 \\
\hline 1 & $\varnothing$ & 0 & 0 & $\varnothing$ & 0 & 0 \\
\hline 2 & 0 & $\emptyset_{1}$ & $\emptyset_{2}$ & 0 & $\emptyset_{1}$ & $\emptyset_{3}$ \\
\hline 3 & 0 & $\emptyset_{2}$ & $\emptyset_{4}$ & 0 & $\emptyset_{2}$ & $\emptyset_{5}$ \\
\hline 4 & $\varnothing$ & 0 & 0 & $\varnothing$ & 0 & 0 \\
\hline 5 & 0 & $\emptyset_{1}$ & $\emptyset_{2}$ & 0 & $\emptyset_{1}$ & $\emptyset_{3}$ \\
\hline 6 & 0 & $\emptyset_{3}$ & $\emptyset_{5}$ & 0 & $\emptyset_{3}$ & $\emptyset_{6}$ \\
\hline
\end{tabular}


By applying the above coefficients, stiffness matrix of the cracked elements is obtained through Eq. (6):

$$
\begin{aligned}
& k_{\text {rracked }_{n}}=E_{n} I_{n}\left(\begin{array}{cccccc}
k_{11_{n}} & 0 & 0 & -k_{11_{n}} & 0 & 0 \\
0 & k_{22 n} & k_{23_{n}} & 0 & -k_{22_{n}} & k_{26_{n}} \\
0 & k_{23_{n}} & k_{33_{n}} & 0 & -k_{23_{n}} & k_{36_{n}} \\
-k_{11_{n}} & 0 & 0 & k_{11_{n}} & 0 & 0 \\
0 & -k_{22_{n}} & -k_{23_{n}} & 0 & k_{22_{n}} & -k_{26_{n}} \\
0 & k_{26_{n}} & k_{36_{n}} & 0 & -k_{26_{n}} & k_{66_{n}}
\end{array}\right) \text {, } \\
& k_{11_{n}}=\frac{1}{L_{n} r_{n}^{2}} \emptyset, \quad k_{22_{n}}=\frac{12}{L_{n}^{3}} \emptyset_{1 n^{\prime}}, k_{23_{n}}=\frac{6}{L_{n}^{2}} \emptyset_{2 n}, \quad k_{26_{n}}=\frac{6}{L_{n}^{2}} \emptyset_{3 n^{\prime}}, k_{33_{n}}=\frac{4}{L_{n}} \emptyset_{4_{n}} \text {, } \\
& k_{36_{n}}=\frac{2}{L_{n}} \emptyset_{5 n}, \quad k_{66_{n}}=\frac{4}{L_{n}} \emptyset_{6 n}, \quad \xi_{n}=\frac{1.5 h}{L\left(1-\beta_{n}^{3}\right)} \ln \left(\frac{1}{\beta_{n}^{3}}\right) \text {, } \\
& D=\beta_{n}^{6} \xi_{n}{ }^{4}-2 \beta_{n}^{3} \xi_{n}{ }^{4}+\xi_{n}{ }^{4}-4 \beta_{n}^{6} \xi_{n}{ }^{3}+4 \xi_{n}{ }^{3}-12 \eta_{n} \beta_{n}^{6} \xi_{n}{ }^{2}+12 \eta_{n} \xi_{n}{ }^{2} \\
& +6 \beta_{n}^{6} \xi_{n}{ }^{2}-6 \xi_{n}{ }^{2}-12 \eta_{n}{ }^{2} \beta_{n}^{6} \xi_{n}+12 \eta_{n}{ }^{2} \xi_{n}+12 \eta_{n} \beta_{n}^{6} \xi_{n}-12 \eta_{n} \xi_{n} \\
& -4 \beta_{n}^{6} \xi_{n}+4 \xi_{n}+\beta_{n}^{6}+2 \beta_{n}^{3}+1 \text {, } \\
& \emptyset_{n}=\frac{3\left(\beta_{n}+1\right)\left(\beta_{n}{ }^{2}+1\right)}{3\left(\beta_{n}{ }^{3}+\beta_{n}{ }^{2}+\beta_{n}+1\right)+\xi_{n} \beta_{n}+\xi_{n} \beta_{n}{ }^{2}-3 \xi_{n} \beta_{n}{ }^{3}+\xi_{n}}, \\
& \emptyset_{1 n}=\frac{2 \beta_{n}^{3}+\beta_{n}^{6}-\left(\beta_{n}^{6}-1\right) \xi_{n}+1}{D} \text {, } \\
& \emptyset_{2 n}=\frac{\xi_{n}\left(2 \eta_{n}-2 \eta_{n} \beta_{n}^{6}\right)-\left(\beta_{n}^{6}-1\right) \xi_{n}^{2}+2 \beta_{n}^{3}+\beta_{n}^{6}+1}{D}, \\
& \emptyset_{3_{n}}=\frac{-\xi_{n}\left(2 \eta_{n}-2 \eta_{n} \beta_{n}^{6}+2 \beta_{n}^{6}-2\right)+\left(\beta_{n}^{6}-1\right) \xi_{n}^{2}+2 \beta_{n}^{3}+\beta_{n}^{6}+1}{D}, \\
& \emptyset_{4_{n}}=\frac{\left(3 \eta_{n}{ }^{2}-3 \eta_{n}{ }^{2} \beta_{n}^{6}\right) \xi_{n}+\left(3 \eta_{n}-3 \eta_{n} \beta_{n}^{6}\right) \xi_{n}{ }^{2}-\left(\beta_{n}^{6}-1\right) \xi_{n}{ }^{3}+2 \beta_{n}^{3}+\beta_{n}^{6}+1}{D}, \\
& \emptyset_{5_{n}}=\frac{\left(6 \eta_{n}{ }^{2} \beta_{n}^{6}-6 \eta_{n}{ }^{2}-6 \eta_{n} \beta_{n}^{6}+6 \eta_{n}\right) \xi_{n}-\left(6 \eta_{n}-6 \eta_{n} \beta_{n}^{6}+3 \beta_{n}^{6}-3\right) \xi_{n}{ }^{2}}{D} \\
& +\frac{\left(2 \beta_{n}^{6}-2\right) \xi_{n}^{3}+2 \beta_{n}^{3}+\beta_{n}^{6}+1}{D}, \\
& \emptyset_{6 n}=\frac{-\left(3 \eta_{n}{ }^{2} \beta_{n}^{6}-3 \eta_{n}{ }^{2}-6 \eta_{n} \beta_{n}^{6}+6 \eta_{n}+3 \beta_{n}^{6}-3\right) \xi_{n}+\left(3 \eta_{n}-3 \eta_{n} \beta_{n}^{6}+3 \beta_{n}^{6}-3\right) \xi_{n}{ }^{2}}{D} \\
& -\frac{\left(\beta_{n}^{6}-1\right) \xi_{n}{ }^{3}+2 \beta_{n}^{3}+\beta_{n}^{6}+1}{D}
\end{aligned}
$$

where, $1-\beta_{n}$ is the crack to section depth ratio, $\eta_{n}$ is the crack location from beginning of the element to element length ratio, $\xi_{n}$ is the crack effective length to element length ratio and $n$ is the element number.

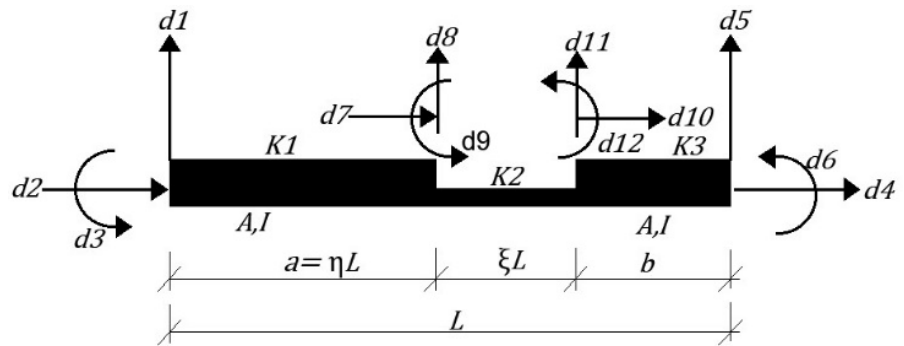

Fig. 3. Cracked beam column element with twelve DOFs 


\subsection{Assembling the global dynamic stiffness matrix}

This matrix is assembled through those of the individual constituent cracked beam-columns. The stiffness matrix of each beam-column in the local coordinate system is transformed into the global coordinate system through Eq. (7) introduced by [26]:

$\mathbf{K}_{\text {Total }}=\mathbf{T}^{T} \mathbf{K}_{\text {Local }} \mathbf{T}$,

where, $\mathbf{T}$ is the transformation matrix.

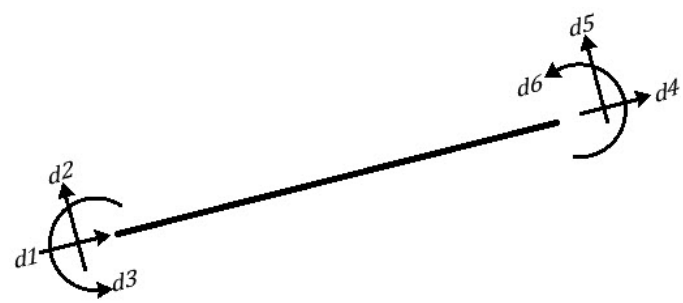

Fig. 4. DOFs in a beam-column element

\section{Numerical studies}

This proposed method is verified through existing four different examples, Table 2.

Table 2. Structural features

\begin{tabular}{|c|c|c|c|c|}
\hline & Example 1 [20] & Example 2 [7] & Example 3 [19] & Example 4 [18] \\
\hline Structure & Beam & Beam & Frame & Frame \\
\hline & Simple & Cantilever & 2 Story -2 Bay & 1 Story -2 Bay \\
\hline Material & Steel & Aluminum & Steel & Steel \\
\hline$E\left(\mathrm{GN} / \mathrm{m}^{2}\right)$ & 200 & 79.69 & 206 & 206 \\
\hline$\rho\left(\mathrm{kg} / \mathrm{m}^{3}\right)$ & 7800 & 2600 & 7675 & 7675 \\
\hline${ }^{*} W(\mathrm{~m})$ & 0.10 & 0.050 & 0.198 & 0.198 \\
\hline$H(\mathrm{~m})$ & 0.20 & 0.025 & 0.122 & 0.122 \\
\hline Beam length $(\mathrm{m})$ & 4 & 0.996 & 6 & 12 \\
\hline \multicolumn{7}{|l}{ Column length $(\mathrm{m})$} & - & - & 3 & 12 \\
\hline${ }^{*} W$ : Element section width
\end{tabular}

\subsection{Example 1}

A simple cracked beam applied in Mehrjoo et al. [20] is considered here. This beam has $4 \mathrm{~m}$ length, $0.1 \mathrm{~m}$ width, and $0.2 \mathrm{~m}$ height. Material is of steel with Poisson's ratio of 0.3 , Table 2 . The beam has a crack with $80 \mathrm{~mm}$ depth located $1.5 \mathrm{~m}$ from the left support, Fig. 5. To validate this proposed method, natural frequencies, static, and dynamic responses of this beam subjects to static and impact loads are obtained and compared to the results extracted from a simulator Abaqus, CAE 2017 software. The cracked region of the deformed beam shape at a specific time step in Abaqus software is shown in Fig. 6.

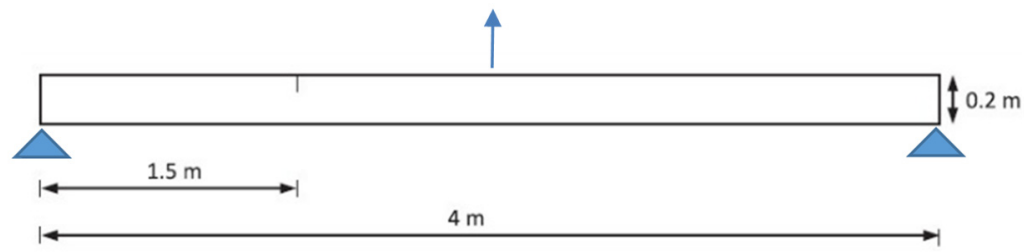

Fig. 5. Simple supported beam of example $1[20]$ 


\subsubsection{Natural frequencies}

These frequencies obtained by Mehrjoo et al. [20], FEM, and these proposed methods are tabulated in Table 3, whereas observed, this proposed method is in a good agreement with its counterparts. The maximum error in this proposed method at second mode is $3.3 \%$.

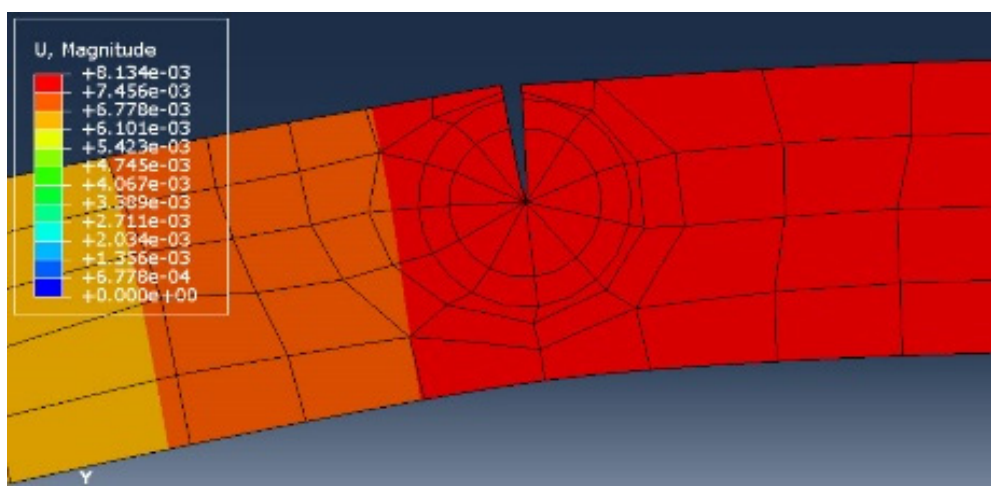

Fig. 6. Crack modelling in Abaqus

Table 3. Natural frequencies obtained by Mehrjoo et al. [20], FEM, and this proposed methods

\begin{tabular}{|c|c|c|c|}
\hline \multicolumn{4}{|c|}{ Natural frequencies of three primary modes } \\
\hline Mode & Mehrjoo et al. [20] & FEM (Abaqus) & Present \\
\hline 1 & 26.75 & 26.62 & 26.46 \\
\hline 2 & 111.64 & 108.82 & 112.45 \\
\hline 3 & 261.19 & 246.42 & 247.99 \\
\hline
\end{tabular}

\subsubsection{Static responses}

An incremental concentrated static force is exerted on the beam at the middle, Fig. 6. Loading begins from $10 \mathrm{kN}$ and increases to $90 \mathrm{kN}$, and the beam is statically analyzed per $10 \mathrm{kN}$ load intervals. The beam center responses are obtained through this proposed and FEM methods, which are compared in Fig. 7. The responses of the two methods are very close to each other and a maximum error of $3.6 \%$ is observed.

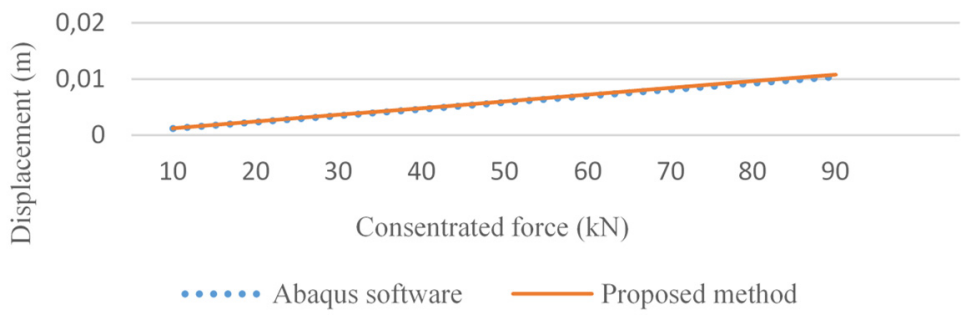

Fig. 7. Displacement of the beam center due to the concentrated static force

\subsubsection{Dynamic responses}

An impact force of $10 \mathrm{kN}$ per $0.01 \mathrm{sec}$ is exerted on the beam at the middle. Damping ratio is assumed to be 0.05 . Numerical analysis is adopted by applying Newmark method. Plots of the results, indicate a periodic motion for the point taken at the middle of the beam, Fig. 6 . The dynamic behavior of this beam is analyzed in 1000 steps with $0.001 \mathrm{sec}$ time step size. This proposed, and FEM methods are adopted by applying MATLAB and Abaqus software's, respectively. By comparing the responses, a maximum error of $7 \%$ is observed, which is below $0.1 \mathrm{~mm}$. 


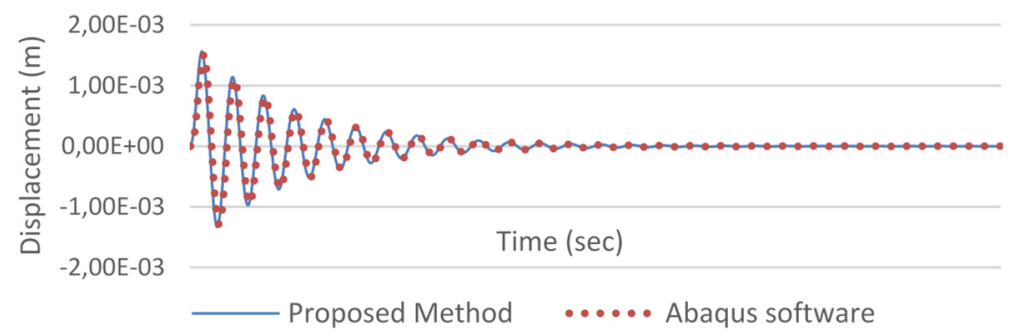

Fig. 8. Displacement of the cracked beam due to impact force at the middle

\subsection{Example 2}

An aluminum cantilever beam with single crack, tested by Sinha et al. [7], is considered here. They obtained the modal parameters of the beam through the impulse response method, using a small instrumented hammer for excitation and an accelerometer of mass $0.0035 \mathrm{~kg}$ to measure the response. The modal test is run on an intact beam and then on the similar beams with a single crack at $275 \mathrm{~mm}$ from the left end and varying depths of 4,8 and $12 \mathrm{~mm}$. The beam is clamped at the left side by longitudinal and rotary springs. Springs' stiffness consist of $k_{t}=26.5 \mathrm{MN} / \mathrm{m}$ and $k_{\theta}=150 \mathrm{kNm} / \mathrm{rad}$, Fig. 9. The details of the geometric dimensions and material properties are tabulated in Table 2 .

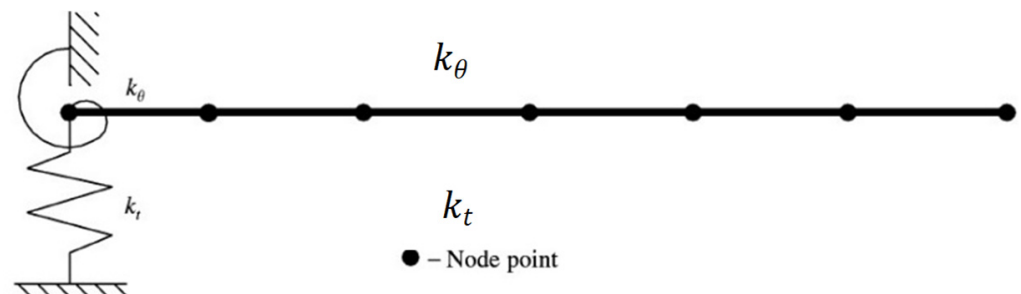

Fig. 9. Cantilever beam of example 2 [7]

The natural frequencies obtained for this cracked beam, by applying this proposed method, are in close agreement with those measured by Sinha et. al. [7] through experimental tests, Table 4 . The maximum error occurs in the first mode of the first scenario and is equal $1.6 \%$.

Table 4. Comparison of proposed and Sinha et. al. [7] methods

\begin{tabular}{|c|c|c|c|c|c|c|c|c|c|}
\hline & \multicolumn{9}{|c|}{ Frequency of four primary modes in three different damage scenarios } \\
\cline { 2 - 10 } & \multicolumn{3}{|c|}{ Scenario 1 } & \multicolumn{3}{c|}{ Scenario 2} & \multicolumn{3}{c|}{ Scenario 3 } \\
\cline { 2 - 9 } & ${ }^{*} \eta L=275 \mathrm{~mm}, 1-\beta=0.16$ & \multicolumn{2}{c|}{$\eta=275 \mathrm{~mm}, 1-\beta=0.32$} & $\eta L=275 \mathrm{~mm}, 1-\beta=0.48$ \\
\cline { 2 - 10 } & New method & Measured [7] & $\%$ Err & New method & Measured [7] & $\%$ Err & New method & Measured [7] & $\%$ Err \\
\hline 1 & 19.680 & 20 & 1.6 & 19.460 & 19.750 & 1.46 & 19.273 & 19 & 1.44 \\
\hline 2 & 123.692 & 124.25 & 0.4 & 122.839 & 124.063 & 0.99 & 122.131 & 123 & 0.71 \\
\hline 3 & 340.803 & 340.813 & 0 & 335.726 & 336.875 & 0.34 & 331.726 & 326.563 & 1.58 \\
\hline 4 & 668.699 & 662.813 & 0.89 & 662.016 & 662.313 & 0.86 & 667.462 & 660.313 & 1.08 \\
\hline
\end{tabular}

\subsection{Example 3}

A two bay, two storey frame that is studied by Labib et al. [19] is considered here, Fig. 10. The frame specifications are tabulated in Table 2. Two different damage scenarios with a single crack are considered. Different cases for the crack location and depth, together with the corresponding first four natural frequencies are tabulated in Table 5.

Each node of the frame, with three degrees of freedom, has two translations and one rotation. The stiffness terms of the members connected at the node are added together to form the global 
stiffness matrix of the frame. The natural frequencies are then calculated for the frame. The above process is programmed through MATLAB. The results reported by Labib et al. [19] and those obtained through this proposed method are compared in Table 5. The cracks are assumed to remain open during the whole process.

The dynamic stiffness matrices for this frame, is obtained through this newly proposed method.

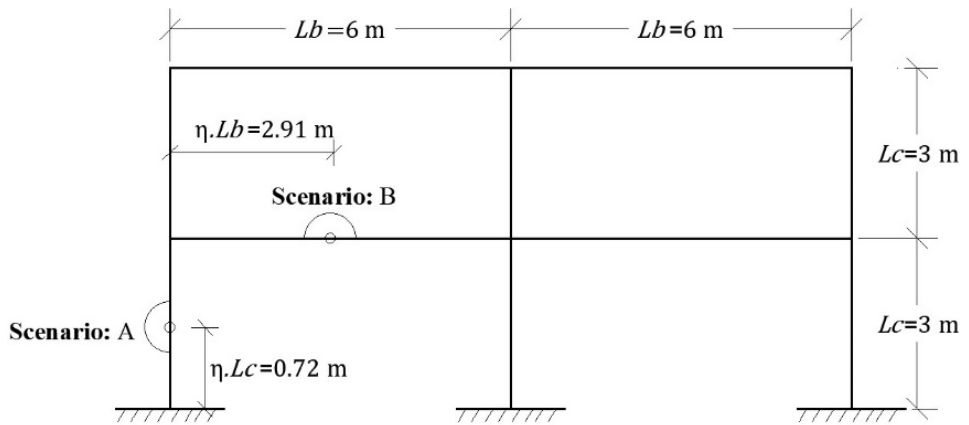

Fig. 10. Two storey, two slab frame of example 3 [19]

Table 5. Comparison of the proposed and Labib et al. [19] methods

\begin{tabular}{|c|c|c|c|c|c|c|c|c|c|}
\hline \multicolumn{10}{|c|}{ Frequency of four primary modes } \\
\hline & \multicolumn{3}{|c|}{ Healthy structure } & \multicolumn{3}{|c|}{$\begin{array}{l}\text { Scenario A, crack depth: } \\
0.2 H, \eta L c=0.72 \mathrm{~m}\end{array}$} & \multicolumn{3}{|c|}{$\begin{array}{c}\text { Scenario B, crack depth: } \\
0.4 H \eta L b=2.91 \mathrm{~m}\end{array}$} \\
\hline Mode & Present & Labib & $\%$ Err & Present & Labib & $\%$ Err & Present & Labib & $\%$ Err \\
\hline 1 & 3.2676 & 3.2676 & 0.003 & 3.2535 & 3.2528 & 0.02 & 3.2668 & 3.2674 & 0.02 \\
\hline 2 & 10.8551 & 10.8528 & 0.021 & 10.8372 & 10.8346 & 0.02 & 10.8512 & 10.8510 & 0.002 \\
\hline 3 & 12.0902 & 12.0841 & 0.050 & 12.0823 & 12.0763 & 0.05 & 12.0556 & 12.0690 & 0.11 \\
\hline 4 & 14.3223 & 14.3204 & 0.083 & 14.3317 & 14.3200 & 0.08 & 14.1148 & 14.2237 & 0.76 \\
\hline
\end{tabular}

\subsection{Example 4}

A two bay, one storey frame with multiple cracks studied by Labib et al. [18] is considered here, Fig. 11. The beams and columns are of the same $L=12.00 \mathrm{~m}$ length. The frame specifications are tabulated in Table 2. Each column is cracked at both the ends that is similar to damages that occur at seismic collapse. Each node of the frame, with three degrees of freedom, has two translations and one rotation. The first five natural frequencies of the frame, for the undamaged and the two other damaged scenarios are tabulated in Table 6 . The natural frequencies obtained by this proposed method match the values reported by Labib et al. [18], with the insignificant error below $1 \%$, Table 6 . The cracks are assumed to remain open during the whole process.

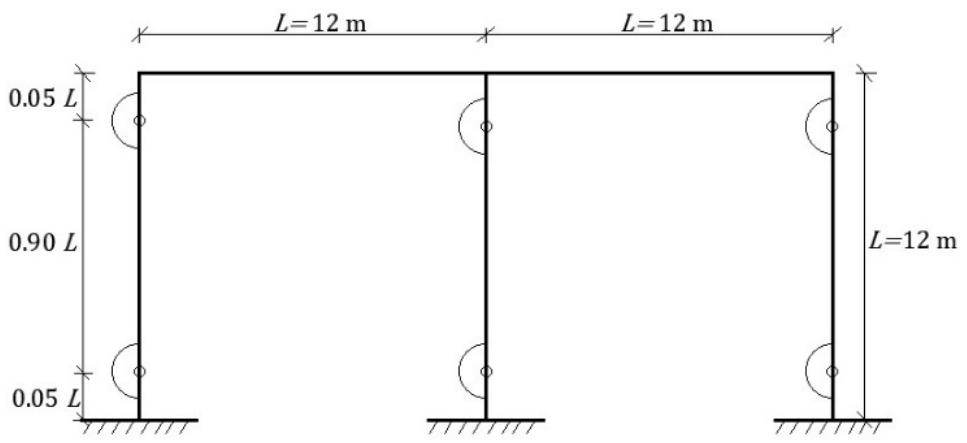

Fig. 11. Two bay, single story frame of example 4 [18] 
Table 6. Comparison of the proposed and Labib et al. [18] methods

\begin{tabular}{|c|c|c|c|c|c|c|c|c|c|}
\hline \multicolumn{10}{|c|}{ Frequency of four primary modes } \\
\hline \multirow{2}{*}{ Mode } & \multicolumn{3}{|c|}{ Healthy structure } & \multicolumn{2}{c|}{ Scenario i, Crack depth: $0.2 \mathrm{H}$} & \multicolumn{3}{|c|}{ Scenario ii, Crack depth: $0.4 \mathrm{H}$} \\
\cline { 2 - 10 } & Present & Labib & \% Err & Present & Labib & \% Err & Present & Labib & \% Err \\
\hline 1 & 0.5987 & 0.5987 & 0 & 0.5868 & 0.5916 & 0.8 & 0.5719 & 0.5771 & 0.90 \\
\hline 2 & 2.4664 & 2.4667 & 0.012 & 2.4518 & 2.4554 & 0.15 & 2.4290 & 2.4335 & 0.19 \\
\hline 3 & 3.1085 & 3.1095 & 0.032 & 3.0946 & 3.0952 & 0.02 & 3.0689 & 3.0693 & 0.68 \\
\hline 4 & 4.1895 & 4.1894 & 0.002 & 4.1544 & 4.1539 & 0.01 & 4.0936 & 4.0847 & 0.20 \\
\hline 5 & 4.5099 & 4.5085 & 0.031 & 4.4625 & 4.4617 & 0.001 & 4.3767 & 4.3637 & 0.30 \\
\hline
\end{tabular}

\section{Sensitivity analysis}

Sensitivity of the Axial $(\phi)$, Shear $(\phi 1)$, and Bending $(\phi 4)$ stiffness components to the crack severity and its location is analyzed here, Figs. 12 to 14. In Figs. 12(a) to 14(a), the crack location ratio $\left(\eta_{n}\right)$ is assumed to be 0.1 , while the effective crack length ratio $\left(\xi_{n}\right)$ is calculated through Eq. (2). In Figs. 12(b) to 14(b), the crack depth ratio $\left(1-\beta_{n}\right)$ is assumed to be 0.3 , while the effective crack length ratio of $\left(\xi_{n}\right)$ is calculated through Eq. (2). Based on Eq. (2) when $1-\beta$, is $0.3, \xi_{n}$ becomes 0.2443 , therefore when $\eta$ exceeds 0.7557 , crack breaks the element boundary and the results are invalid. In this case, the alternative is to move the nodes of the model in a direction until the crack effective length is contained within the single element. In all cases, when the crack depth exceeds $0.8 H$, a sudden reduction occurs, and the element becomes instable. The minimum stiffness reduction occurs when the crack is located near the middle of the element.

According to Fig. 12(a), the axial stiffness reduction is within $0-20 \%$ when the crack depth is within $0 \%-80 \%$. For a crack depth of $50 \%$ a reduction of $8 \%$ occurs. The axial stiffness is not sensitive to the crack location, Fig. 12(b).

According to Fig. 13(a), variation of crack depth from zero to $0.5 H$, leads to a shear stiffness reduction from zero to $14 \%$. In Fig. 13(b), in situations where the crack is at the ends of the element limits, maximum reduction occurs at the shear stiffness, which reaches to $15 \%$ at a crack depth ratio of 0.3 .

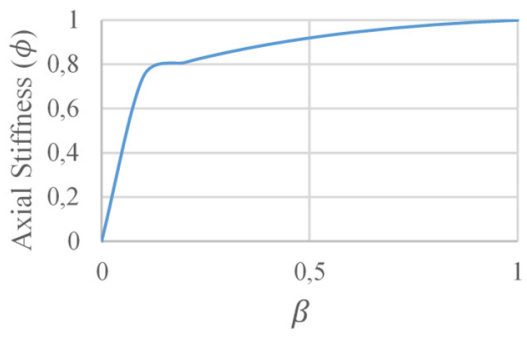

a)

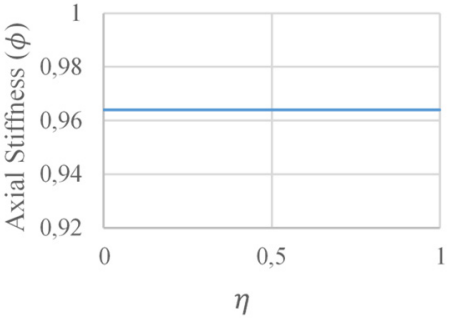

b)

Fig. 12. Axial stiffness variations: a) in terms of damage severity, b) in terms of damage Location

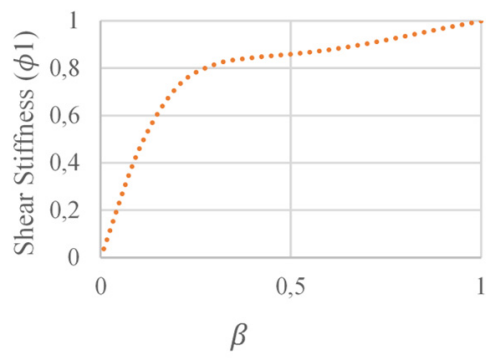

a)

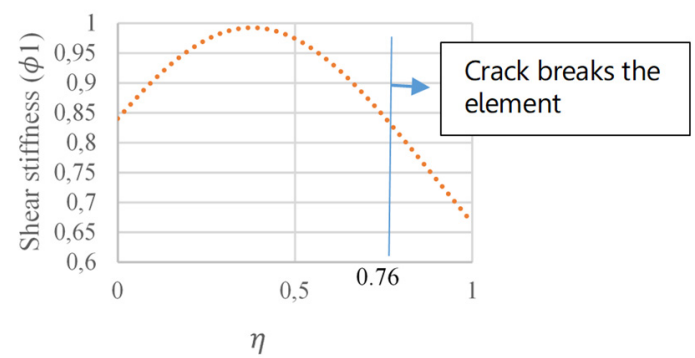

b)

Fig. 13. Shear stiffness variations: a) in terms of damage severity, b) in terms of damage location 


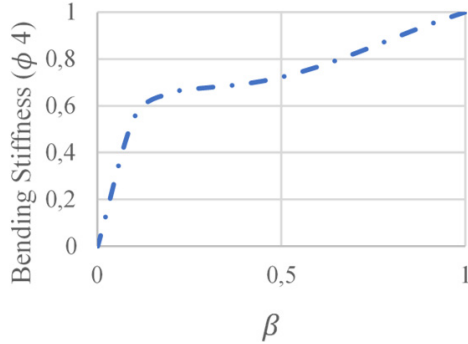

a)

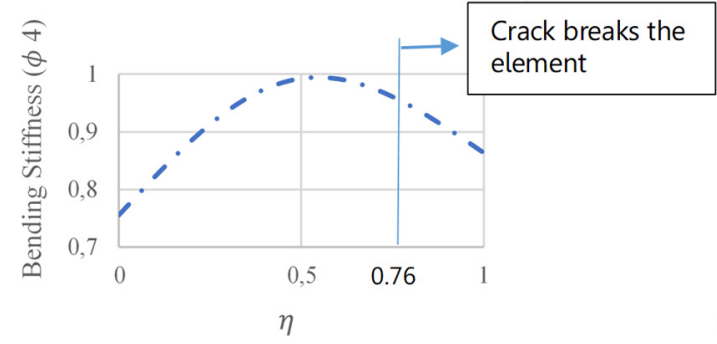

b)

Fig. 14. Bending stiffness variations: a) in terms of damage severity, b) in terms of damage location

Based on Fig. 14(a), the variation of crack depth from zero to $0.5 \mathrm{H}$, leads to bending stiffness reduction from zero to $28 \%$. In Fig. 14(b) where the crack is close to element boundary, the maximum reduction of $18 \%$ occurs.

\section{Conclusions}

The methodology proposed in this article is contributive in more parametric analysis of damaged structures. Applying the model reduction of static condensation approach, crack sides' DOFs are condensed and a new six by six-stiffness matrix is introduced for the first time in this field. Each component of the obtained stiffness matrix is divided by its relevant component of the intact element that yields seven dimensionless coefficients. By applying these coefficients, the sensitivity analysis of stiffness matrix to crack parameters is run in a more accurate, simple and fast manner. Low sensitivity of axial stiffness, moderate sensitivity of shear stiffness, and relatively high sensitivity of bending stiffness to the crack parameters constitute the findings in this study. The crack depth of $0.5 \mathrm{H}$, leads to a reduction of $28 \%, 14 \%$, and $8 \%$ for bending, shear, and axial stiffness, respectively. When the crack depth exceeds $0.8 \mathrm{H}$, a sudden reduction in stiffness coefficients occurs and the element becomes instable. Shear and bending stiffness reduction varies in different crack location. When the crack is close to element boundaries, maximum reduction occurs in shear and bending stiffness matrix.

\section{Acknowledgement}

The authors like to extend their appreciation to Mr. Hidook Vartevan for his contribution in proofreading.

\section{References}

[1] Belytschko T., Ventura G., Xu J. New methods for discontinuity and crack modeling in EFG. Meshfree Methods for Partial Differential Equations, 2003, p. 37-50.

[2] Bouboulas A., Anifantis N. Finite element modeling of a vibrating beam with a breathing crack: observations on crack detection. Structural Health Monitoring, Vol. 10, Issue 2, 2011, p. 131-145.

[3] Kishen J. C., Kumar A. Finite element analysis for fracture behavior of cracked beam-columns. Finite Elements in Analysis and Design, Vol. 40, Issue 13, 2004, p. 1773-1789.

[4] Casciati S. Stiffness identification and damage localization via differential evolution algorithms. Structural Control and Health Monitoring, Vol. 15, Issue 3, 2008, p. 436-449.

[5] Caddemi S., Caliò I. The exact explicit dynamic stiffness matrix of multi-cracked Euler-Bernoulli beam and applications to damaged frame structures. Journal of Sound and Vibration, Vol. 332, Issue 12, 2013, p. 3049-3063.

[6] Christides S., Barr A. One-dimensional theory of cracked Bernoulli-Euler beams. International Journal of Mechanical Sciences, Vol. 26, Issue 11, 1984, p. 639-648.

[7] Sinha J., Friswell M., Edwards S. Simplified models for the location of cracks in beam structures using measured vibration data. Journal of Sound and Vibration, Vol. 251, Issue 1, 2002, p. 13-38. 
[8] Carneiro S., Inman D. Comments on the free vibrations of beams with a single-edge crack. Journal of Sound and Vibration, Vol. 244, Issue 4, 2001, p. 729-736.

[9] Caddemi S., et al. A novel beam finite element with singularities for the dynamic analysis of discontinuous frames. Archive of Applied Mechanics, Vol. 83, Issue 10, 2013, p. 1451-1468.

[10] Shen M.-H., Pierre C. Free vibrations of beams with a single-edge crack. Journal of Sound and Vibration, Vol. 170, Issues 2-17, 1994, p. 237-259.

[11] Wahab M. A., De Roeck G., Peeters B. Parameterization of damage in reinforced concrete structures using model updating. Journal of Sound and Vibration, Vol. 228, Issue 4, 1999, p. 717-730.

[12] Leme S., Aliabadi M. Dual boundary element method for dynamic analysis of stiffened plates. Theoretical and Applied Fracture Mechanics, Vol. 57, Issue 1, 2012, p. 55-58.

[13] Neves A., Simões F., Da Costa A. P. Vibrations of cracked beams: discrete mass and stiffness models. Computers and Structures, Vol. 168, 2016, p. 68-77.

[14] Pathak H., et al. A simple and efficient XFEM approach for 3-D cracks simulations. International Journal of Fracture, Vol. 181, Issue 2, 2013, p. 189-208.

[15] Sukumar N., et al. Meshless methods and partition of unity finite elements. International Journal of Forming Processes, Vol. 8, 2005, p. 4-409.

[16] Yazdi A. K., Shooshtari A. Analysis of cracked truss type structures. Asian Journal of Civil Engineering, Vol. 15, Issue 4, 2014, p. 517-533.

[17] Yazdi A. K., Shooshtari A. Analysis of cracked skeletal structures by utilizing a cracked beamcolumn element. Theoretical and Applied Fracture Mechanics, Vol. 85, 2016, p. 276-282.

[18] Labib A., Kennedy D., Featherston C. Free vibration analysis of beams and frames with multiple cracks for damage detection. Journal of Sound and Vibration, Vol. 333, Issue 20, 2014, p. 4991-5003.

[19] Labib A., Kennedy D., Featherston C. Crack localisation in frames using natural frequency degradations. Computers and Structures, Vol. 157, 2015, p. 51-59.

[20] Mehrjoo M., Khaji N., Ghafory Ashtiany M. Application of genetic algorithm in crack detection of beam-like structures using a new cracked Euler-Bernoulli beam element. Applied Soft Computing, Vol. 13, Issue 2, 2013, p. 867-880.

[21] Qu Z.-Q. Static Condensation, in Model Order Reduction Techniques. Springer, 2004, p. 47-70.

[22] Wilson E. L. The static condensation algorithm. International Journal for Numerical Methods in EngineeringVol. 8, Issue 1, 1974, p. 198-203.

[23] Ghee Koh C., Ming See L., Balendra T. Damage detection of buildings: numerical and experimental studies. Journal of Structural Engineering, Vol. 121, Issue 8, 1995, p. 1155-1160.

[24] Li H., Wang J., James Hu S.-L. Using incomplete modal data for damage detection in offshore jacket structures. Ocean Engineering, Vol. 35, Issue 17, 2008, p. 1793-1799.

[25] Escobar J. A., Sosa J. J., Gómez R. Structural damage detection using the transformation matrix. Computers and Structures, Vol. 83, Issue 4, 2005, p. 357-368.

[26] Howson W. A compact method for computing the eigenvalues and eigenvectors of plane frames. Advances in Engineering Software, Vol. 1, Issue 4, 1979, p. 181-190.

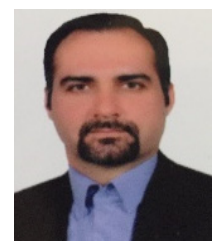

Davari obtained his M.S. degree in structural engineering from Ferdosi University of Mashhad, Mashhad, Iran, in 2004. He is Ph.D. candidates since 2014. His current research interests include control, dynamics and fault diagnosis.

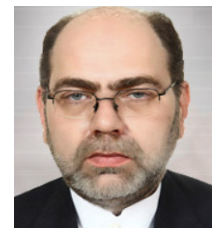

Khanlari obtained his Ph.D. degree in structural engineering from Science and Research Branch, Islamic Azad University, Tehran, Iran, in 2006. Currently, he is an Assistant Professor in earthquake engineering. His current research interests include control, dynamics and fault diagnosis. 
2885. SENSITIVITY OF BEAM-COLUMN ELEMENT STIFFNESS MATRIX TO THE CRACK PARAMETERS.

PEIMAN DAVARI DOLATABADI, KAREN KHANLARI, MOHSEN GHAFORY ASHTIANY, MAHMOOD HosSEINI

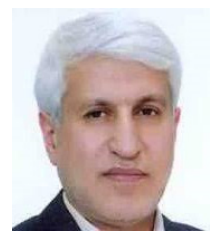

Ashtiany obtained his Ph.D. degree in earthquake engineering from Virginia Polytechnic Institute and State University, USA, in 1983. He is full Professor in earthquake engineering. His current research interests include seismology and earthquake engineering.

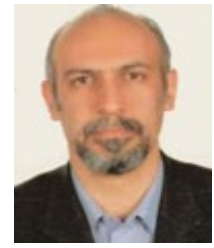

Hosseini obtained his Ph.D. degree in structural engineering from Science and Research Branch, Islamic Azad University, Tehran, Iran. He is an Associate Professor in earthquake engineering. His current research interests include seismology and earthquake engineering. 